\title{
DETERMINANTS OF FOOD INSECURITY AMONG CONGREGATE MEAL PARTICIPANTS: A CROSS-SECTIONAL STUDY USING PARTICIPANT INFORMATION MATCHED TO GEOGRAPHIC AND SERVICE PROVIDER DATA
}

\author{
J. Mabli ${ }^{1}$, M. Shenk ${ }^{1}$
}

\begin{abstract}
Background: As people age, they are more likely to face financial, medical, and mobility related challenges that can put them at risk of food insecurity. This is a serious public health concern that has been associated with many adverse health outcomes. Objectives: This study examined factors associated with food insecurity among older adults who receive congregate meals from the Administration on Aging's Nutrition Services Program. Combining participant, geographic, and provider data allowed for a more detailed assessment of older adult food insecurity than is typically possible using other national surveys. Design: A cross-sectional study. We conducted a cross-sectional data analysis using national survey data from the Administration on Aging's Nutrition Services Program Outcomes Survey, conducted from 2015 to 2016. The data were linked to provider data from the meal site where participants ate. Logistic regression analysis was conducted to estimate the associations between food insecurity and demographic, household, geographic, and provider-level characteristics and circumstances. Setting: Interviews with congregate meal participants were conducted in person at congregate meal sites or another preferred place. Participants: A total of 520 older adults were included as study participants. All older adults were participating in the Nutrition Services Program and receiving congregate meals at the time of the survey interview. All participants were at least 67 years old. Measurements: This study used a 6-item food security measure as the dependent variable. Older adults who answered at least 3 of the 6 questions affirmatively were considered food insecure. Food security was assessed over a 30-day recall period. Results: $18 \%$ of congregate meal participants lived in food insecure households. Among congregate meal participants, having low income, difficulty reaching family and friends, past military service, and mobility challenges, and attending a site that provided nutrition counseling were associated with increased food insecurity (most odds ratios ranged from 1.1 to 2.6). Older age, geographic access to food, certain chronic health conditions, and provideroffered nutrition screening and social activities reduced the odds of experiencing food insecurity (most odds ratios ranged from 0.2 to 0.4 ). Conclusions: Although the Nutrition Services Program helps to alleviate food insecurity, a nontrivial percentage of participants remain food insecure. Nutrition programs can help address clients' food access limitations by broadening nutrition screenings at meal sites to include more comprehensive assessments based on non-traditional risk factors for food insecurity.
\end{abstract}

Key words: Food access, nutrition services program, older adult nutrition, nutrition screeners, local providers.

\section{Introduction}

Having adequate access to food is essential to older adults' health and quality of life. Adequate food access ensures that older adults can consume vital nutrients, maintain a healthy weight, and meet calorie and energy levels, all of which can reduce the risk of and improve the management of chronic disease (1). As people age, however, they are more likely to face financial, medical, and mobility related challenges that can put them at risk of food insecurity-experiencing food access limitations due to a lack of money or other resources (2). According to the U.S. Department of Agriculture (USDA), 7.5\% of

1. Mathematica, Cambridge, MA, USA

Corresponding Author: James Mabli, Mathematica, 955 Massachusetts Avenue, Cambridge, MA 02139, USA, jmabli@mathematica-mpr.com, Phone: 617-301-8997, Fax: 617-491-8044
U.S. households that contained an older adult were food insecure in fiscal year 2018 (2). Studies have shown food insecurity rates for poor households with older adults were nearly four times as large as the national average among older adults (11).

Food insecurity is a serious public health concern that has been associated with many adverse health outcomes, including increased risk of heart disease, stroke, pulmonary disease, and diabetes $(3,4)$; obesity and mental health disorders $(5,6,7)$; and chronic disease, depression, and hospitalization $(8,9,10)$. The adverse health outcomes associated with older adult food insecurity are especially concerning because of the increase over time in the rate of food insecurity among older adults and the continuing demographic shift towards an older population. Between the start of the recession in 2007 and 2018, the rate of food insecurity among households with older adults increased by $15.4 \%$ 
$(2,12)$. Accounting for the aging of the population, there was a $65.1 \%$ increase over the same time period in the absolute number of food insecure households with older adults.

These trends underscore the importance of learning more about the determinants of food insecurity among older adults. Therefore, the purpose of this study is to use individual and community characteristics from a unique combination of data sources to provide a more detailed assessment of the correlates of older adult food insecurity than is typically possible using other national surveys. This article uses new data from a recent, national evaluation of participants in the Older Americans Act Title IIIC-1 Nutrition Services Program (NSP) to examine the determinants of food insecurity among NSP participants (13). Administered by the Administration on Aging (AoA) within the Administration for Community Living of the U.S. Department of Health and Human Services (DHHS), the NSP strives to reduce food insecurity and promote health and well-being by providing congregate and home-delivered meals, nutrition education, nutrition-risk screening, and nutrition counseling to older adults. Meals, recreational activities, and other services are provided in congregate sites located in senior centers, schools, churches, and other community settings and are targeted towards older adults with the greatest economic or social need.

\section{Methods}

\section{Data}

The data used are primarily from AoA's NSP Outcomes Survey, conducted from 2015 to 2016; 596 interviews with congregate meal participants were conducted in person at congregate meal sites. The survey was based on a national probability sample obtained using a multistage sampling design in which the stages corresponded to different entities in the aging networkan informal network of providers that administer the NSP_including local service providers (LSPs) that typically provide meals and services directly to participants.

Agency surveys on program administration were conducted with a sample of LSPs from more than half of the Area Agencies on Aging (AAA) in the U.S. Each LSP provided the research team with a list of the meal sites it operated. Interviewers randomly selected meal participants by interviewing every nth person that arrived, where " $n$ " depended on the number of participants meal sites expected to attend that day, and collected information in a computer-assisted personal interview.

Although most of the data are from program participants who completed the NSP outcomes survey, we linked the data to information on agency characteristics from the LSP survey conducted with staff from 190 LSPs from 2014 to 2015. We also geocoded NSP participants' address information provided in the survey to link the participant data to the 2010-2014 American Community Survey summary file to obtain community characteristics, the Economic Research Service food environment atlas to determine whether a participant lived in an urban or rural area (14), a food retailer address database from the USDA to measure geographic access to food, and county-level unemployment rate data from the Bureau of Labor Statistics (15).

\section{Outcome measure}

Our outcome measure is whether a NSP participant's household was food insecure in the 30 days before the interview. The survey used a 6-item food security module-a subset of the 18 questions used in the Current Population Survey (CPS) - because of concerns about older respondents experiencing survey fatigue; this shorter module is typically used as an alternative to the 18 -item module to decrease respondent burden $(16,17)$. Its main weakness relative to the 18-item module is that it does not satisfactorily capture the more severe range of food insecurity (16). The following questions made up the 6-item module:

1. The food that I/we bought just didn't last and I/ we didn't have money to get more (was that often, sometimes, or never true)?

2. I/we couldn't afford to eat balanced meals (was that often, sometimes, or never true)?

3. Did anyone in your household ever cut the size of their meals or skip meals because there wasn't enough money to buy food (yes/no)?

4. How many days did this happen?

5. Did you ever eat less than you felt you should because there wasn't enough money to buy food (yes / no)?

6. Were you ever hungry but didn't eat because you couldn't afford enough food (yes/no)?

Our outcome was a binary measure equal to 1 if the household was food insecure and 0 if it was food secure. Following the guidelines used by the USDA, a household was classified as food insecure if the participant answered at least three of the six questions affirmatively (16). Affirmative responses consist of "often," "sometimes," "yes," or "at least 3 out of 30 days."

\section{Covariates}

The comprehensiveness of the survey data allowed us to include a wide range of variables in the analysis:

\section{Demographic characteristics}

We included a standard set of variables measuring participants' demographic characteristics: age; gender 
(female relative to male), highest grade completed (high school, some college, and college or higher, relative to less than high school); marital status (widowed, married, or living with partner, relative to divorced, separated, or never married); veteran status; and race and ethnicity (non-Hispanic black; non-Hispanic other, which includes Asian, American Indian, and other non-white and nonblack races; and Hispanic, relative to non-Hispanic white).

\section{Economic characteristics}

We included indicators for whether participants were employed, relative to not being employed; their annual income relative to the DHHS federal poverty guidelines; and their receipt of income from Social Security Disability Insurance or unemployment compensation, Supplemental Security Income, a pension or retirement fund, General Assistance, or family or relatives.

\section{Social connections}

These variables captured participants' living arrangements and connection to others in the community. We included variables measuring whether the participant lived alone; lived with grandchildren; belonged to any religious or social groups, book clubs, or other organizations; or reported having difficulty getting in touch with others when they needed to in the past two weeks (responses of "almost always," "most of the time," and "about half the time" were coded as 1, versus "occasionally" or "not at all," which were coded as 0 ).

\section{Health indicators}

We included measures of participants' health: whether a doctor diagnosed the participant with high blood pressure or diabetes; the number of falls in the past three months; whether the participant had serious difficulty walking or climbing stairs; and whether the participant had serious difficulty concentrating, remembering, or making decisions because of a physical, mental, or emotional condition.

\section{Community characteristics}

We included continuous variables defined at the census tract level measuring the percentages of the population that are non-white, Hispanic, and without access to a vehicle. We also included the county unemployment rate.

\section{Geographic identifiers}

We included indicators for whether the participant's census tract was in an urban or rural area and whether they lived in the Northeast, Midwest, or West, relative to the South.

\section{Measures of geographic access to food}

A measure of geographic access was included that indicated that at least one supermarket, superstore, or large grocery store was within 1 mile of a participant's residential address for those in an urban area and within 10 miles of their address for those in a rural areacommon distance thresholds in food access analyses (18).

\section{LSP characteristics}

We included indicators for whether the LSP that provided meals and services to the participant was a public organization, relative to a private nonprofit organization; was a standalone organization, relative to being part of another organization; and offered nutrition counseling, nutrition screening, or social activities through a grant or contract with the AAA. We also created a measure of size of the LSP by measuring whether the number of full time equivalents (FTEs) was higher than the median number of FTEs, relative to being at or below the median.

\section{Statistical analysis}

We estimated descriptive statistics with weighted data using percentages for binary measures and means for continuous and discrete variables. We used multivariate logistic regression analysis to examine associations of food insecurity (a binary outcome measure) with all participant and LSP characteristics included in the model. We used the svy suite in Stata 15 to account for the survey's multistage sampling design and estimated standard errors using a variance estimator based on a first-order Taylor series approximation. We used sampling weights to account for the sample design and to adjust for differences in nonresponse propensities across respondent groups. The sample weights make the estimates in this article nationally representative of the population of congregate meal participants at the time of the survey.

Recognizing the potential of overfitting the model, we also estimated a more parsimonious model specification based on a stepwise backward covariate selection algorithm. Although our findings were robust to using the restricted model, we present findings from the unrestricted specification to highlight the comprehensive set of potential determinants of food insecurity available in the data. 
Table 1

Characteristics of the study participants $(n=520)$

\begin{tabular}{|c|c|c|c|c|c|}
\hline Variable & $\%$ & $\#$ or SD & Variable & $\%$ & \# or SD \\
\hline Dependent variable & & & Connections & & \\
\hline Food insecure & 18.1 & 94 & Lives alone & 63.8 & 332 \\
\hline Demographic & & & Lives with grandchildren & 5.6 & 29 \\
\hline Age (mean years) & 76.9 & 7.1 & Belongs to a religious or social group & 63.1 & 328 \\
\hline Female & 66.0 & 343 & Had difficulty getting in touch & 12.9 & 67 \\
\hline Highest level of school completed & & & Health & & \\
\hline Less than HS (reference) & 22.7 & 118 & Falls in the past three months (mean) & 0.4 & 0.9 \\
\hline High school graduate, GED, or equivalent & 30.2 & 157 & $\begin{array}{l}\text { High blood pressure/hypertension or diabetes/high } \\
\text { blood sugar }\end{array}$ & 75.7 & 394 \\
\hline Some college (no degree) & 33.7 & 175 & Difficulty walking or climbing stairs & 33.2 & 172 \\
\hline Associate, bachelor's, master's professional school, or doctorate & 13.3 & 69 & $\begin{array}{l}\text { Serious difficulty concentrating, remembering, or making } \\
\text { decisions }\end{array}$ & 14.3 & 74 \\
\hline Marital status & & & Area characteristics & & \\
\hline Married or living with partner & 23.8 & 124 & $\%$ of population nonwhite (mean) & 22.8 & 25.3 \\
\hline Widowed & 46.1 & 240 & $\%$ of population Hispanic (mean) & 15.5 & 22.5 \\
\hline Divorced, separated, or never married (reference) & 30.0 & 156 & $\%$ of housing units without access to a vehicle (mean) & 7.8 & 12.9 \\
\hline Veteran & 16.5 & 86 & County unemployment (mean) & 5.8 & 2.3 \\
\hline Race/ethnicity & & & Geographic characteristics & & \\
\hline Non-Hispanic white (reference) & 64.2 & 334 & Urban & 72.8 & 378 \\
\hline Non-Hispanic black & 13.4 & 70 & Rural (reference) & 27.2 & 142 \\
\hline Non-Hispanic other & 8.7 & 45 & Midwest & 23.3 & 121 \\
\hline Hispanic & 13.7 & 71 & Northeast & 26.4 & 138 \\
\hline Economic & & & South (reference) & 15.9 & 83 \\
\hline Monthly income-to-poverty (mean) & 1.6 & 1.0 & West & 34.4 & 179 \\
\hline Sources of income & & & Food access & & \\
\hline Full-time or part-time work & 15.5 & 81 & Has access to supermarket & 80.4 & 418 \\
\hline Social Security & 96.8 & 503 & LSP characteristics & & \\
\hline SSDI or workers' compensation & 8.1 & 42 & Public organization & 25.8 & 134 \\
\hline SSI & 13.1 & 68 & Standalone organization & 60.9 & 317 \\
\hline Pension or retirement fund & 48.5 & 252 & High FTEs & 39.3 & 204 \\
\hline General assistance & 2.9 & 15 & Nutrition counseling & 23.0 & 119 \\
\hline \multirow[t]{2}{*}{ Money from relatives } & 4.1 & 21 & Nutrition screening or assessment & 52.7 & 274 \\
\hline & & & Social activities & 67.2 & 349 \\
\hline
\end{tabular}

SD: standard deviation; SSDI: Social Security Disability Insurance; SSI: Supplemental Security Income; LSP: local service provider; FTEs: full time equivalents.

\section{Results}

\section{Descriptive statistics}

Of the 596 congregate meal participants who were interviewed, 76 individuals who did not provide income, race, or ethnicity information were excluded from the analytic sample. Compared to respondents with incomplete information, the analytic sample of congregate meal participants had a higher food insecurity rate $(18 \%$ versus $5.3 \%, \mathrm{p}=0.044)$ and was more likely to live alone (64\% versus $38 \%, \mathrm{p}=0.010$ ).

The percentage of congregate meal participants living in food insecure households was 18\% (Table 1). Most participants were poor or near-poor, most lived alone and some reported having had difficulty getting in touch with others. The majority reported having diagnosed chronic conditions and many had difficulty walking or climbing stairs. Some participants did not have nearby access to a food store. Participants attended LSPs that were predominantly standalone, private organizations that offered nutrition counseling and screening and social activities. 
Table 2

Odds ratio estimates for being food insecure among congregate meal participants compared to food secure congregate meal participants from a multivariate logistic regression model

\begin{tabular}{|c|c|}
\hline Variable & OR $(90 \% \mathrm{CI})$ \\
\hline \multicolumn{2}{|l|}{ Demographic } \\
\hline Age & $0.90(0.86-0.95)^{* * *}$ \\
\hline Female & $1.17(0.52-2.65)$ \\
\hline High school graduate, GED, or equivalent & $1.50(0.59-3.82)$ \\
\hline Some college (no degree) & $0.95(0.37-2.44)$ \\
\hline Associate, bachelor's, master's professional school, or doctoral degree & $1.50(0.48-4.68)$ \\
\hline Married or living with partner & $1.02(0.32-3.23)$ \\
\hline Widowed & $0.80(0.39-1.61)$ \\
\hline Veteran & $4.38(1.28-15.06)^{*}$ \\
\hline Non-Hispanic black & $0.52(0.17-1.62)$ \\
\hline Non-Hispanic other & $0.72(0.18-2.97)$ \\
\hline Hispanic & $1.51(0.35-6.57)$ \\
\hline \multicolumn{2}{|l|}{ Economic } \\
\hline Monthly income-to-poverty ratio & $0.17(0.08-0.37)^{* * *}$ \\
\hline \multicolumn{2}{|l|}{ Sources of income } \\
\hline Full-time or part-time work & $1.26(0.62-2.58)$ \\
\hline SSDI or workers' compensation & $0.89(0.41-1.93)$ \\
\hline SSI & $0.67(0.22-2.03)$ \\
\hline Pension or retirement fund & $0.65(0.32-1.32)$ \\
\hline General assistance & $1.54(0.39-6.08)$ \\
\hline Money from relatives & $0.15(0.03-0.84)^{*}$ \\
\hline \multicolumn{2}{|l|}{ Social } \\
\hline Lives alone & $0.88(0.35-2.22)$ \\
\hline Lives with grandchildren & $0.75(0.22-2.52)$ \\
\hline Belongs to a religious or social group & $1.18(0.50-2.79)$ \\
\hline Had difficulty getting in touch with others in the past two weeks & $2.56(1.27-5.15)^{* *}$ \\
\hline \multicolumn{2}{|l|}{ Health } \\
\hline Falls in the past three months & $1.51(1.15-1.99)^{* \star}$ \\
\hline Diagnosis of high blood pressure/hypertension or diabetes/high blood sugar & $0.27(0.11-0.66)^{* *}$ \\
\hline Serious difficulty walking or climbing stairs & $1.94(1.20-3.16)^{* \star}$ \\
\hline Serious difficulty concentrating, remembering, or making decisions & $1.99(0.88-4.49)$ \\
\hline \multicolumn{2}{|l|}{ Area characteristics } \\
\hline$\%$ of population nonwhite & $0.99(0.98-1.01)$ \\
\hline$\%$ of population Hispanic & $0.97(0.95-1.00)^{*}$ \\
\hline$\%$ of housing units without access to a vehicle & $1.05(1.02-1.08)^{* * *}$ \\
\hline County unemployment & $1.18(1.01-1.39)^{*}$ \\
\hline \multicolumn{2}{|l|}{ Geographic characteristics } \\
\hline Urban & $3.36(1.22-9.27)^{\star *}$ \\
\hline Midwest & $0.93(0.39-2.23)$ \\
\hline Northeast & $0.48(0.17-1.36)$ \\
\hline West & $1.04(0.40-2.70)$ \\
\hline
\end{tabular}


Table 2 (continued)

Odds ratio estimates for being food insecure among congregate meal participants compared to food secure congregate meal participants from a multivariate logistic regression model

\begin{tabular}{lc}
\hline Variable & OR (90\% CI) \\
\hline Food access & $0.31(0.13-0.76)^{* *}$ \\
Has a superstore or large grocery store within 1 mile (urban) or 10 miles (rural) & $0.81(0.33-2.01)$ \\
LSP characteristics & $1.09(0.43-2.75)$ \\
Public organization & $1.09(0.54-2.21)$ \\
Standalone organization & $6.59(2.74-15.88)^{* * *}$ \\
High FTEs & $0.22(0.12-0.42)^{\star * *}$ \\
Provides nutrition counseling & $0.44(0.23-0.86)^{* *}$ \\
Provides nutrition screening and assessment & \\
Provides social activities & \\
\hline CI: confidence interval; SSDI: Social Security Disability Insurance; SSI: Supplemental Security Income; LSP: local service provider; FTEs: full time equivalents. ${ }^{*} \mathrm{p}<.10$.
\end{tabular}

\section{Associations between food insecurity and participant, area, and LSP characteristics}

Table 2 shows odds ratios (ORs) from the logistic regression analysis. An additional year of age was associated with having $10 \%$ lower odds of being food insecure $(\mathrm{OR}=0.90, \mathrm{p}<0.001)$ and being a veteran was associated with having much higher odds of being food insecure $(\mathrm{OR}=4.38, \mathrm{p}=0.050)$, compared to not being a veteran. Income had the strongest association with food insecurity; the odds of being food insecure were $83 \%$ lower $(\mathrm{OR}=0.17, \mathrm{p}<0.001)$ for participants with income equal to $200 \%$ of poverty compared to those with income equal to $100 \%$ of poverty. The source of income matters as well because the odds of being food insecure were $85 \%$ lower and marginally significant $(\mathrm{OR}=0.15$, $\mathrm{p}=0.071$ ) for participants who received money from relatives, compared to those who did not. Participants who reported having difficulty getting in touch with others were more than twice as likely to be food insecure $(\mathrm{OR}=2.56, \mathrm{p}=0.029)$, compared to those who did not have difficulty.

Several health variables were associated with food insecurity. Reporting having been diagnosed with high blood pressure or diabetes was associated with having $73 \%$ lower odds of being food insecure $(\mathrm{OR}=0.27$, $\mathrm{p}=0.017$ ). Participants who had experienced a greater number of recent falls or who had serious difficulty walking or climbing stairs were more likely to be food insecure. An additional fall in the past three months was associated with being 1.5 times more likely to be food insecure $(\mathrm{OR}=1.51, \mathrm{p}=0.016)$, whereas having difficulty walking or climbing stairs was associated with being 1.9 times more likely $(\mathrm{OR}=1.94, \mathrm{p}=0.026)$.

Among participants' community and geographic characteristics, having a lower percentage of people in their community who were Hispanic, or a higher percentage who did not have access to a vehicle, were unemployed, or lived in an urban area, were associated with being food insecure. Having greater geographic access to food was associated with being less likely to be food insecure (OR=0.31, $\mathrm{p}=0.033$ ).

Finally, several characteristics of the LSP that provided participants with meals and services were associated with food insecurity. Participants who received meals and services from an LSP that offered nutrition counseling were more than six times more likely to be food insecure (OR=6.59, $\mathrm{p}<0.001)$, compared to those that attended LSPs that did not offer this. In contrast, those who received meals or services from an LSP that offered nutrition screening or social activities had $78 \%(\mathrm{OR}=0.22, \mathrm{p}<0.001)$ and $56 \%(\mathrm{OR}=0.44, \mathrm{p}=0.044)$ lower odds, respectively, compared to those that attended LSPs without these services.

The findings were robust to using a restricted model (Table 3). All statistically significant associations in the full model remained significant in the restricted model and three variables that were not statistically significant in the full model became significant in the restricted model (being non-Hispanic black; having difficulty concentrating, remembering, or making decisions; and living in the Northeast).

\section{Discussion}

National surveys like the CPS and National Health and Nutrition Examination Survey are useful for monitoring changes in food insecurity, but they do not contain sufficient information on the characteristics and circumstances specific to older adults that may be associated with being food insecure. The findings based on the unique combination of data sources in this study contribute valuable information to the literature on older adult food insecurity.

Several of the demographic and economic predictors 
Table 3

Odds ratio estimates for being food insecure among congregate meal participants compared to food secure congregate meal participants from a restricted multivariate logistic regression model

\begin{tabular}{|c|c|}
\hline Variable & OR $(90 \% \mathrm{CI})$ \\
\hline \multicolumn{2}{|l|}{ Demographic } \\
\hline Age & $0.90(0.86-0.94)^{* * *}$ \\
\hline Veteran & $4.37(1.55-12.34)^{* *}$ \\
\hline Non-Hispanic black & $0.36(0.16-0.84)^{\star *}$ \\
\hline \multicolumn{2}{|l|}{ Economic } \\
\hline Monthly income-to-poverty ratio & $0.18(0.10-0.31)^{\star \star \star}$ \\
\hline \multicolumn{2}{|l|}{ Sources of income } \\
\hline Money from relatives & $0.22(0.08-0.62)^{* *}$ \\
\hline \multicolumn{2}{|l|}{ Social } \\
\hline Had difficulty getting in touch with others in the past two weeks & $2.35(1.16-4.73)^{\star *}$ \\
\hline \multicolumn{2}{|l|}{ Health } \\
\hline Falls in the past three months & $1.47(1.14-1.88)^{\star *}$ \\
\hline Diagnosis of high blood pressure/hypertension or diabetes/high blood sugar & $0.28(0.12-0.62)^{\star \star}$ \\
\hline Serious difficulty walking or climbing stairs & $1.85(1.22-2.79)^{\star *}$ \\
\hline Serious difficulty concentrating, remembering, or making decisions & $1.84(1.02-3.31)^{*}$ \\
\hline \multicolumn{2}{|l|}{ Area characteristics } \\
\hline$\%$ of population Hispanic & $0.97(0.96-0.99)^{* * *}$ \\
\hline$\%$ of housing units without access to a vehicle & $1.05(1.03-1.07)^{\star * *}$ \\
\hline County unemployment & $1.17(1.00-1.36)^{*}$ \\
\hline \multicolumn{2}{|l|}{ Geographic characteristics } \\
\hline Urban & $3.21(1.37-7.52)^{\star *}$ \\
\hline Northeast & $0.41(0.22-0.74)^{\star *}$ \\
\hline \multicolumn{2}{|l|}{ Food access } \\
\hline Has a superstore or large grocery store within 1 mile (urban) or 10 miles (rural) & $0.36(0.16-0.81)^{\star *}$ \\
\hline \multicolumn{2}{|l|}{ LSP characteristics } \\
\hline Provides nutrition counseling & $5.30(2.73-10.30)^{\star * *}$ \\
\hline Provides nutrition screening and assessment & $0.23(0.13-0.41)^{* * *}$ \\
\hline Provides social activities & $0.50(0.31-0.80)^{\star \star}$ \\
\hline
\end{tabular}

CI: confidence interval; LSP: local service provider; ${ }^{*} \mathrm{p}<.10 .{ }^{* *} \mathrm{p}<.05 .{ }^{* * *} \mathrm{p}<.01$

of food insecurity were consistent with findings from prior research. NSP participants are less likely to be food insecure the older they are $(19,20,21)$; however, this relationship is not well understood because higher health care costs and reduced physical capabilities with age should limit the extent to which older adults can access sufficient amounts of food $(22,23)$. Given the adverse health outcomes associated with being food insecure, addressing food insecurity at an earlier age could lower the chances of participants experiencing adverse health events or acquiring new or additional chronic conditions.

Veterans were more likely than non-veterans to be food insecure. Because our empirical model accounts for factors associated with both veteran status and food security, such as being a racial or ethnic minority or poor, the association may reflect the mental health issues that veterans endure or even sleep issues that interfere with a veteran's ability to work and earn income, which in turn can lead to fewer resources for food $(21,24)$.

Consistent with prior research, income was a main determinant of food insecurity $(19,25)$. Our study provides evidence that it is not only the amount of income that matters, but the source of income as well. This is consistent with a national evaluation which found that receiving money from relatives was a key differentiator between low-income participants who were food secure and those who were food insecure (26).

Studies have found that living alone increases the odds of being food insecure (27), as does living in a multigenerational household (28). We found neither to 
be true among NSP participants. However, participants who reported experiencing greater difficulty reaching others had more than twice the odds of being food insecure compared to those who did not experience these challenges. Given the importance of support networks among social determinants of health $(29,30)$, practitioners should consider incorporating expanded measures of social networks into food security assessments rather than relying solely on within-home household composition.

The majority of health variables included in our model were associated with food insecurity. Experiencing falls and having difficulty walking or climbing stairs were associated with greater odds of being food insecure, which is consistent with other studies (20). Although good nutrition and adequate dietary intake have been cited as modifiable risk factors for fall prevention in older adults $(31,32)$, falls can reduce the extent to which older adults have sufficient access to food by limiting their ability to live independently, including traveling to purchase food and preparing food within the home (23, 33).

Participants with high blood pressure or diabetes were less likely to be food insecure. This is a counterintuitive finding because managing these chronic diseases requires careful meal planning and medication administration, which can increase non-food costs and reduce an older adult's financial ability to meet his or her food needs $(8,34,35)$. Our study's contrasting finding may reflect the fact that these studies focus on populations and geographies that are different from our study. In addition, NSP participants by definition already have access to health promotion and disease management services through LSPs, which allows them simultaneously to address their food needs and to manage their chronic conditions.

Community and geographic characteristics were important determinants of food insecurity. Participants who lived in an urban area or an area with more limited vehicle access were more likely to be food insecure, whereas those who lived in areas with greater access to supermarkets, superstores, and large grocery stores were less likely. Food insecurity may be more likely in urban areas because of higher housing costs and food prices, compared to rural areas $(36,37)$. At the same time, there is more limited geographic access to food in rural areas (18) and, regardless of urbanicity, having access to a vehicle has been associated with lower food insecurity $(38,39)$. Our findings underscore the importance of ensuring sufficient access to food for older adults by having retailers located close to home and having access to a vehicle.

Finally, LSPs offer a variety of services that help participants meet their health and nutrition needs. Participants in our study who attended meal sites that offered nutrition counseling were more likely to be food insecure, whereas those who attended LSPs that offered nutrition screening and social activities were less likely to be food insecure. These findings may reflect that nutrition screening is conducted among many congregate meal participants at a meal site without knowing participants' food needs, whereas nutrition counseling is offered only to those participants in need of one-on-one discussions related to specific nutritional risk criteria. The AARP Foundation has documented how, in recent years, food security screenings have been embedded in broader nutrition and health screenings conducted at primary care and community partner organizations (40). Our finding suggests that offering nutrition screening at meal sites may be a means through which to assess an older adult's risk factors for food insecurity and provide client-specific nutrition counseling to those who are at risk.

\section{Study limitations}

These findings should be interpreted in the context of several limitations. First, because food security is a household-level outcome measure, it captures the circumstances of all household members. However, because most participants live alone and we included many household-level variables in our model, using an outcome measure defined at the household level should not affect our findings substantially. Second, because of the design effects introduced from the multistage sampling design, it was not possible to conduct analyses using subsamples of participants to explore whether associations differed by participant type. Third, we measured geographic access to food using a national map of food retailers. Although these are stores where participants could potentially shop, using data on actual food shopping locations would allow us to understand older adults' food access and acquisition and learn more about coping strategies they use to meet their food needs. Finally, the current study relied on self-reports of diagnoses received from doctors rather than a more comprehensive picture that could be obtained using administrative data.

These limitations are offset by several strengths of the current study, including using a recent, nationally representative sample of participants to examine the determinants of food insecurity and using matched geographic and provider data that up until now have not been used in the context of older adult food insecurity research. In doing so, we were able to expand the set of standard correlates of food insecurity from income, age, and health to provide a more comprehensive assessment based on measures of social connections, geography, food access, and service receipt.

This study also helps to explain why some NSP participants remain food insecure despite receiving congregate meals through the program. Knowing the factors that contribute to older adult food insecurity, especially for people who already receive program services, has important public health implications because it allows policymakers and practitioners to target these groups for specific screenings and services. 
Further exploration of the determinants of food insecurity among older adults should focus on social connections, older adult health and management of chronic conditions, geographic access to food in the communities in which older adults live, and non-nutrition program services such as opportunities for socialization, transportation, and nutrition screening and counseling. Together, this information will allow practitioners to help older adults successfully meet their food needs and ensure their health and well-being.

Funding: This material is based upon work supported by the Department of Health and Human Services, Administration for Community Living, Administration on Aging (HHSP233201500035I/HHSP23337001T). The authors have no conflicts of interest to disclose. The views expressed in this article are those of the authors and do not necessarily reflect the position or policy of the Department of Health and Human Services or the United States government. AoA had no role in the design or conduct of the study; in the collection, analysis, and interpretation of data; or in the preparation of the manuscript. AoA reviewed a draft of the manuscript.

Ethical standards: All ethical guidelines for both the NSP outcomes survey and the LSP survey were met, and the study was approved by the New England Institutional Review Board (protocol number 120160370).

Conflicts of Interest: The authors have no conflicts of interest to disclose.

\section{References}

1. U.S. Department of Agriculture; 2018. Older adults. https://www. choosemyplate.gov/browse-by-audience/view-all-audiences/adults/olderadults. Accessed January 13, 2020.

2. Coleman-Jensen A, Rabbitt MP, Gregory CA, Singh A. Household food security in the United States in 2018. ERR-270, U.S. Department of Agriculture, Economic Research Service; 2019.

3. Alley DE, Soldo BJ, Pagán JA, McCabe J, deBlois M, Field SH, Asch DA, Cannuscio C. Material resources and population health: Disadvantages in health care, housing, and food among adults over 50 years of age. Am J Public Health. 2009; 99(S3), S693-S701.

4. Franklin B, Jones A, Love D, Puckett S, Macklin J, White-Means S. Exploring mediators of food insecurity and obesity: A review of recent literature. J Community Health. 2012; 37(1), 253-264.

5. Laraia BA. Food insecurity and chronic disease. Adv Nutr. 2013; 4(2), 203212.

6. Seligman HK, Schillinger D. Hunger and socioeconomic disparities in chronic disease. N Engl J Med. 2010; 363, 6-9.

7. Heflin CM, Siefert K, Williams DR. Food insufficiency and women's mental health: Findings from a 3-year panel of welfare recipients. Soc Sci Med. 2005; 61(9), 1971-1982.

8. Seligman HK, Laraia BA, Kushel MB. Food insecurity is associated with chronic disease among low-income NHANES participants. J Nutr. 2010; 140, 304-310.

9. Seligman HK, Bindman AB, Vittinghoff E, Kanaya AM, Kushel MB. Food insecurity is associated with diabetes mellitus: Results from the National Health Examination and Nutritional Examination Survey 1999-2002. J Gen Intern Med. 2007; 22, 1018-1023.

10. Tarasuk V. Household food insecurity with hunger is associated with women's food intakes, health and household circumstances. J Nutr. 2001; 131, 2670-2676.

11. Ziliak J, Gundersen C. The state of senior hunger in America 2015: An annual report: Supplement. National Foundation to End Senior Hunger; 2017.

12. Nord M, Andrews M, Carlson S. Household food security in the United States, 2007. U.S. Department of Agriculture, Economic Research Service; 2008.

13. Mabli J, Gearan E, Cohen R, Niland K, Redel N, Panzarella E, \& Carlson B. Evaluation of the effect of the Older Americans Act Title III-C Nutrition Services Program on participants' food security, socialization, and diet quality. Washington, DC: U.S. Department of Health and Human Services, Administration for Community Living; 2017.

14. Economic Research Service, U.S. Department of Agriculture; 2016. Food access research atlas. http://www.ers.usda.gov/data-products/food-accessresearch-atlas.aspx. Accessed January 13, 2020.

15. Bureau of Labor Statistics. Labor force statistics from the Current Population
Survey. https:/ / data.bls.gov/timeseries/lns14000000. Accessed January 13, 2020.

16. Bickel G, Nord M, Price C, Hamilton W, Cook J. Guide to measuring household food security, revised (technical report). U.S. Department of Agriculture, Food and Nutrition Service; 2000.

17. Gundersen C, Engelhard E, Hake M. The determinants of food insecurity among food bank clients in the United States. J Consum Aff. 2017; 51(3), 501-518.

18. Ver Ploeg M, Breneman V, Farrigan T, Hamrick K, Hopkins D, Kaufman P, et al.. Access to affordable and nutritious food: Measuring and understanding food deserts and their consequences. U.S. Department of Agriculture, Economic Research Service; 2009.

19. Ziliak JP, Gundersen C. Food insecurity among older adults. AARP Foundation; 2011.

20. Lee JS, Frongillo EA. Factors associated with food insecurity among U.S elderly persons: Importance of functional impairments. J Gerontol. 2001; 56(2), S94-S99.

21. Wang EA, McGinnis KA, Goulet J, Bryant K, Gibert C, Leaf DA, ...Veterans Aging Cohort Study Project Team. Food insecurity and health: Data from the Veterans Aging Cohort Study. Public Health Rep. 2015; 130(3), 261-268.

22. Lee JS. Food insecurity and healthcare costs: Research strategies using local, state, and national data sources for older adults. Adv Nutr. 2013; 4(1), 42-50.

23. Wallace SP, Molina LC, Jhawar M. Falls, disability and food insecurity present challenges to healthy aging. UCLA Center for Health Policy Research; 2007.

24. Widome R, Jensen A, Bangerter A, Fu SS. Food security among veterans of the U.S. wars in Iraq and Afghanistan. Public Health Nutr. 2015; 18(5), 844-849.

25. Brostow DP, Gunzburger E, Thomas KS. Food insecurity among veterans: Findings from the Health and Retirement Study. J Nutr Health Aging. 2017; 21(10), 1358-1364.

26. Edin K, Boyd M, Mabli J, Ohls J, Worthington J, Greene S, Redel N, \& Sridharan S. (2013). SNAP food security in-depth interview study. Final report submitted to the Food and Nutrition Service, United States Department of Agriculture. Alexandria, VA: U.S. Department of Agriculture, Food and Nutrition Service. Retrieved from https: / fns-prod.azureedge.net/ sites/default/files/SNAPFoodSec.pdf

27. Strickhouser S, Wright JD, Donley AM. Food insecurity among older adults: Full report [2015 update]. AARP Foundation; 2014.

28. Ziliak JP, Gundersen C. Multigenerational families and food insecurity. South Econ J. 2016; 82(4), 1147-1166.

29. Healthy People 2020. Determinants of health. https:/ / www.healthypeople. gov/2020/about/foundation-health-measures / Determinants-ofHealth\# social. Accessed January 13, 2020.

30. House JS. Social support and social structure. Sociol Forum. 1987; 2(1), 135146.

31. Richardson B. The impact of nutrition on preventing falls. Nutrition \& Foodservice Edge. https://www.anfponline.org/docs/default-source/ legacy-docs/docs/nc122015.pdf. Accessed January 13, 2020.

32. Zoltick ES, Sahni S, McLean RR, Quach L, Casey VA, Hannan MT. Dietary protein intake and subsequent falls in older men and women: The Framingham Study. J Nutr Health Aging. 2011; 15, 147-152.

33. Jin J. Prevention of falls in older adults. J Am Med Assoc. 2018; 319(16), 1734.

34. Gucciardi E, Vahabi M, Norris N, Del Monte JP, Farnum C. The intersection between food insecurity and diabetes: A review. Curr Nutr Rep. 2014; 3(4), 324-332.

35. Irving SM, Njai RS, Siegel PZ. Food insecurity and self-reported hypertension among Hispanic, black, and white adults in 12 states, Behavioral Risk Factor Surveillance System, 2009. Prev Chronic Dis. 2014; 11, 140190.

36. Mabli J. Supplemental Nutrition Assistance Program (SNAP) participation and urban and rural food security. Washington, DC: U.S. Department of Agriculture, Food and Nutrition Service; 2014. Retrieved from https://fnsprod.azureedge.net/sites/default/files/SNAPFS_UrbanRural.pdf

37. Ziliak J, Gundersen C. Senior hunger in the United States: Differences across states and rural and urban areas. Meals on Wheels Association of America; 2009.

38. Martinez JC, Clark JM, Gudzune KA. Association of personal vehicle access with lifestyle habits and food insecurity among public housing residents. Prev Med Rep. 2019; 13, 341-345.

39. Ver Ploeg M, Mancino L, Todd JE, Clay DM, Scharadin B. Where do Americans usually shop for food and how do they travel to get there? Initial findings from the National Household Food Acquisition and Purchase Survey (Economic Research Report No. EIB-138). U.S. Department of Agriculture, Economic Research Service; 2015.

40. Pooler J, Hoffman V, Karva F, Levin M, Lewin-Zwerdling A. Addressing food insecurity in primary care models for patient screening and referral. AARP Foundation and IMPAQ International; 2016. 